\title{
Gender-specific Effect of Micronutrient on Non- erosive Reflux Disease and Erosive Esophagitis
}

\author{
Su Youn Nam, ${ }^{1,2 *}$ Bum Joon Park, ${ }^{2}$ Yeong-Ah Cho, ${ }^{3}$ and Kum Hei Ryu ${ }^{2}$ \\ ${ }^{I}$ Department of Gastroenterology, Center for Gastric Cancer, Kyungpook National University Hospital, Buk-gu, Daegu, Korea; ${ }^{2}$ Department of \\ Internal Medicine, Center for Cancer Prevention \& Detection, National Cancer Center, Goyang; Gyeonggi-do, Korea; and ${ }^{3}$ Department of Clinical \\ Nutrition, National Cancer Center, Goyang; Gyeonggi-do, Korea
}

\section{Background/Aims}

The effect of dietary micronutrients on non-erosive reflux disease (NERD) and reflux esophagitis is unclear. We aim to evaluate the gender-specific effect of micronutrient on erosive esophagitis and NERD.

\section{Methods}

A total of 11690 participants underwent endoscopy and completed 3-day recordings for dietary intake and questionnaires for reflux symptoms from 2004 to 2008. To evaluate the effect of dietary micronutrients on NERD or erosive esophagitis, adjusted regression analysis with odds ratio (OR) and 95\% confidence interval (Cl) was used. In addition, we performed gender-specific analysis.

\section{Results}

Prevalence of NERD and erosive esophagitis was $6.8 \%$ and $11.2 \%$ in men and $9.1 \%$ and $2.4 \%$ in women. In adjusted analysis, high intake of vitamin $\mathrm{A}(\mathrm{OR}, 0.78 ; 95 \% \mathrm{Cl}, 0.64-0.96)$, retinol $(\mathrm{OR}, 0.73 ; 95 \% \mathrm{Cl}, 0.59-0.90)$, vitamin $\mathrm{B} 2(\mathrm{OR}, 0.68 ; 95 \% \mathrm{Cl}, 0.54$ 0.87), vitamin $\mathrm{B} 6(\mathrm{OR}, 0.75 ; 95 \% \mathrm{Cl}, 0.58-0.96)$, folic acid $(\mathrm{OR}, 0.77 ; 95 \% \mathrm{Cl}, 0.62-0.96)$, calcium $(\mathrm{OR}, 0.66 ; 95 \% \mathrm{Cl}, 0.53-0.82)$, and iron $(\mathrm{OR}, 0.68 ; 95 \% \mathrm{Cl}, 0.53-0.87)$ had an inverse association with NERD. However, erosive esophagitis has no relationship with micronutrients except vitamin $\mathrm{C}(\mathrm{OR}, 0.78 ; 95 \% \mathrm{Cl}, 0.62-0.98)$. High dietary intake of calcium reduced the risk of NERD in men and high dietary intake of many micronutrients reduced NERD in women.

\section{Conclusions}

While many dietary micronutrients reduced NERD, they had no effect on erosive esophagitis. The effect of micronutrient on NERD was more prominent in women than men.

(J Neurogastroenterol Motil 2019;25:82-90)

\section{Key Words}

Esophagitis; Gender identity; Micronutrients; Non-erosive reflux disease

Received: July 6, 2018 Revised: September 9, 2018 Accepted: September 28, 2018

(a) This is an Open Access article distributed under the terms of the Creative Commons Attribution Non-Commercial License (http://creativecommons. org/licenses/by-nc/4.0) which permits unrestricted non-commercial use, distribution, and reproduction in any medium, provided the original work is properly cited.

${ }^{*}$ Correspondence: Su Youn Nam, MD, PhD Department of Gastroenterology, Kyungpook National University Hospital, School of Medicine, Kyungpook National University, 807 Hoguk-ro, Buk-gu, Daegu 41404, Korea Tel: +82-53-200-2610, Fax: +82-53-200-2028, E-mail: nam20131114@gmail.com 


\section{Introduction}

Gastroesophageal reflux disease (GERD) is common in the world $^{1-3}$ and is a multifactorial disease. Although some foods may induce GERD, study results for reflux inducing foods have conflicts. ${ }^{4-8}$ In a previous large study, many food groups were strongly associated with non-erosive reflux disease (NERD) but not with erosive esophagitis. ${ }^{9}$ However, a rare study presented the association between dietary micronutrient and GERD. ${ }^{4}$ Although some dietary micronutrients looks to be associated with Barrett's esophagus, ${ }^{10,11}$ dietary micronutrients had no effect on GERD., ${ }^{4,12}$

Even if NERD shares pathogenesis and risk factors with erosive esophagitis, NERD and erosive esophagitis have many different phenotypes. ${ }^{13}$ Responsiveness of proton pump inhibitors (PPI) is higher in erosive esophagitis than NERD. ${ }^{13}$ Thus, we estimated the effect of micronutrients on NERD and erosive esophagitis in a large health screening population. Recent studies suggested gender difference in many diseases. In our previous study, the effect of dietary food group on erosive esophagitis and NERD had gender differences. ${ }^{9}$ Therefore we further analyzed the gender-specific effect of dietary micronutrient on NERD and erosive esophagitis.

\section{Materials and Methods}

\section{Study Population}

This was a cross-sectional study from health check-up population at the National Cancer Center, Korea. ${ }^{9}$ Participants underwent comprehensive health screening from September 2004 to December 2008. Participants undergoing previous gastric surgery, subjects who did not undergo endoscopy or Helicobacter pylori tests, current users of PPI, or incomplete responders of questionnaire were excluded (Figure). The National Cancer Center Institutional Review Board approved this study (No. NCCNCS-10359). Written informed consent were obtained from subjects before endoscopy.

\section{Questionnaire Assessment}

Demographic data (age, gender, chronic diseases, medication history, alcohol consumption, and smoking status), gastrointestinal symptoms, and dietary intake were collected before endoscopy. The questionnaires included typical GERD symptoms (heartburn and acid regurgitation) and atypical symptoms (globus sensation, hoarseness, epigastric soreness, and chronic cough). ${ }^{14}$ Smoking and alcohol drinking status were classified as current (daily or occasionally) or noncurrent. Current means daily or occasional users within the recent 1 year. Noncurrent means never users or past users.

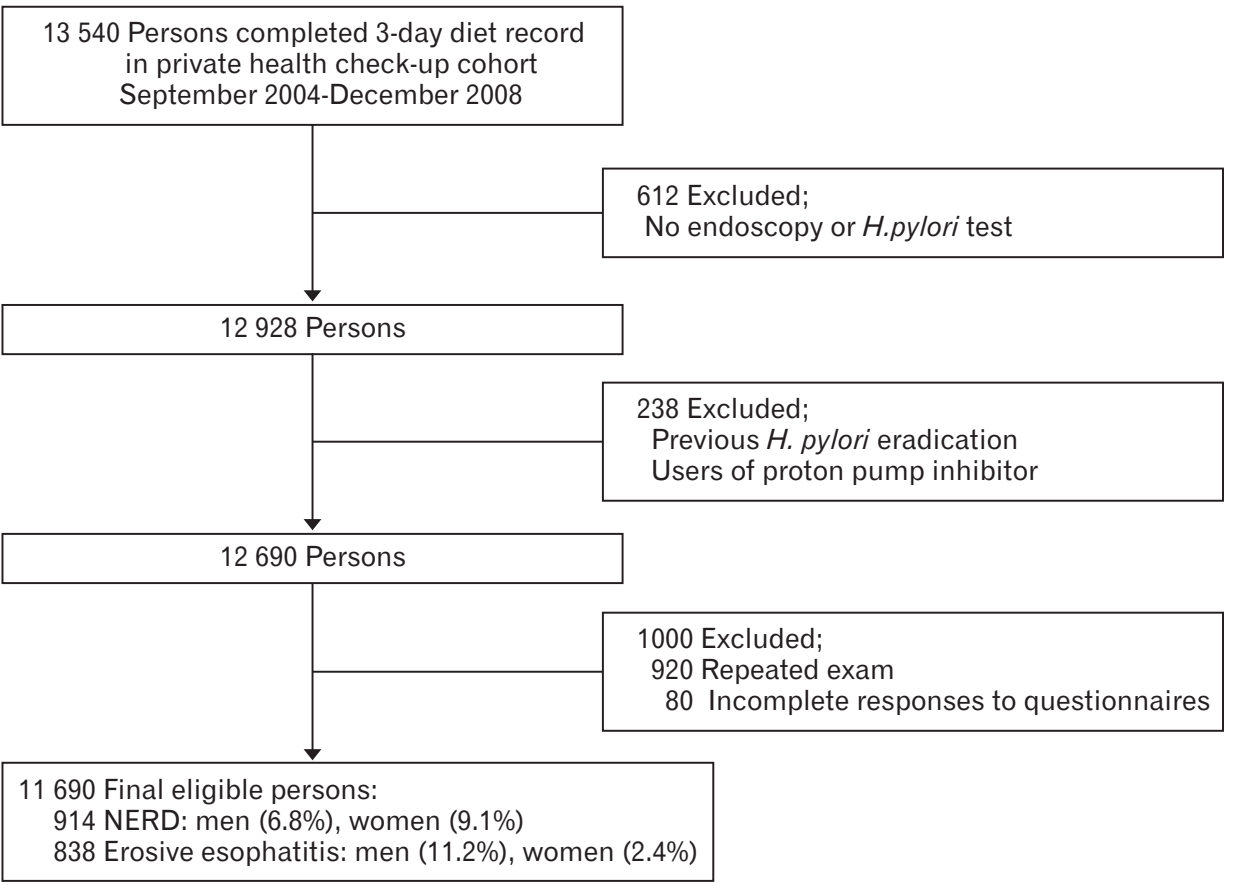

Figure. Study flow of health check-up cohort. H. pylori, Helicobacter pylori. 
Weight and height were measured (InBody Co, Ltd, Seoul, Korea), and body mass index (BMI) was calculated as weight/height ${ }^{2}(\mathrm{~kg} /$ $\left.\mathrm{m}^{2}\right)$.

\section{Dietary Assessment}

We used a 3-day diet record to assess dietary intake of nutrients. ${ }^{9}$ We described the assessment process in a previous study. ${ }^{9}$ In summary, participants recorded both type and amount of all foods consumed during three days, including 2 days among the weekday and one weekend day before health check-up. On the examination day, dietitians interviewed the participants for the accuracy of the food record, and they discussed the recorded contents with participants using real-size food models (Korea Mirage Replica Inc., Incheon, Korea), measuring spoons, measuring cups, and eye measurements of foods that were assisted by photographs (Korean Nutritionist Association, 1999). ${ }^{9}$ Data based on the results of the dietary intake records were analyzed using the CAN-Pro 3.0 Nutrient Database (The Korean Nutrition Society, Seoul, South Korea) and converted into each nutrient.

\section{Endoscopy}

Erosive esophagitis was defined as endoscopic esophagitis and NERD was defined as weekly typical GERD symptoms without endoscopic esophagitis. Subjects who had fasted overnight underwent under conscious sedation using a flexible endoscope (Q260; Olympus Optical Co, Ltd, Tokyo, Japan). ${ }^{14}$ Specialized gastroenterologists performed the endoscopy. The severity of reflux esophagitis was measured according to the Los Angeles classification system. ${ }^{15}$ Hiatal hernia was recorded if the gastroesophageal junction extended at least $2 \mathrm{~cm}$ above the diaphragmatic hiatal impression during quiet respiration. During endoscopic examination, $H$. pylori infection was evaluated using the rapid urease test (Pronto Dry; Medical Instruments Corporation, Solothurn, Switzerland). ${ }^{16}$

\section{Statistical Methods}

Chi-square tests or $t$ tests were used to compare the differences between the 2 groups (normal vs NERD and normal vs erosive esophagitis) for demographic characteristics. Demographic characteristics included age, gender, BMI, smoking status, and drinking status. We used $t$ test to measure differences of each nutrient between the 2 groups.

For regression analysis of dietary nutrients, they were categorized to quartiles. Nutrients were categorized to 3 groups to analyse the gender-specific effect on GERD because of sample size and GERD prevalence. Contributing factors for erosive esophagitis and NERD were evaluated by regression analysis using odds ratios (OR) and 95\% confidence intervals (CI). Age, gender, total energy intake, BMI, presence of $H$. pylori, presence of hiatal hernia, smoking, and alcohol consumption were adjusted. Dietary micronutrients showing differences between control and GERD in univariate analysis were additionally adjusted. For gender-specific analysis, we classified micronutrients into three groups (tertile). We further analysed the gender-specific effect of micronutrient on NERD and erosive esophagitis.

We used STATA software (version 12; College Station, Texas, USA). All statistical tests were two-sided, and $P$-values less than 0.05 were considered statistically significant.

\section{Results}

\section{Characteristics of Participants and Intake of Micronutrients}

A total of 11690 participants were finally included (Figure). ${ }^{13}$ The prevalence of NERD and erosive esophagitis was $6.8 \%$ and $11.2 \%$ in men and $9.1 \%$ and $2.4 \%$ in women (Table 1). BMI, presence of $H$. pylori, presence of hiatal hernia, current smoker, and current drinker were markedly higher in men than in women (Table 1). Table 2 provides intake of total energy and micronutrients in control, NERD, and erosive esophagitis. Total energy intake had no statistical difference between control and NERD but several micronutrient intakes had a difference between control and NERD in $t$ test (Table 2). However, dietary intakes of total energy and many micronutrient markedly differed between control and erosive esophagitis in $t$ test (Table 2).

Table 1. Characteristics of Participants by Gender

\begin{tabular}{lcc}
\hline \multicolumn{1}{c}{ Contributing factors } & $\begin{array}{c}\text { Men } \\
(\mathrm{n}=6276)\end{array}$ & $\begin{array}{c}\text { Women } \\
(\mathrm{n}=5414)\end{array}$ \\
\hline NERD (n [\%]) & $424(6.8)$ & $490(9.1)$ \\
Erosive esophagitis (n [\%]) & $706(11.2)$ & $132(2.4)$ \\
Age (mean [SD], yr) & $50.4(9.7)$ & $49.0(9.5)$ \\
Body mass index (mean [SD]) & $24.2(2.8)$ & $22.8(2.9)$ \\
Current smoker (n [\%]) & $2653(42.3)$ & $280(5.2)$ \\
Current drinker (n [\%]) & $5097(82.1)$ & $2349(44.9)$ \\
Presence of H. pylori (n [\%]) & $3215(51.2)$ & $2535(47.0)$ \\
Presence of hiatal hernia (n [\%]) & $174(2.8)$ & $35(0.6)$ \\
\hline
\end{tabular}

NERD, non-erosive reflux disease; H. pylori, Helicobacter pylori. 
Table 2. Comparison of Dietary Micronutrient Intake for Erosive Esophagitis and Non-erosive Reflux Disease

\begin{tabular}{|c|c|c|c|c|c|}
\hline Contents of micronutrients & $\begin{array}{c}\text { Control } \\
(\mathrm{n}=9938)\end{array}$ & $\begin{array}{l}\text { NERD } \\
(\mathrm{n}=914)\end{array}$ & $P$-value ${ }^{\mathrm{a}}$ & $\begin{array}{l}\text { Erosive esophagitis } \\
\qquad(\mathrm{n}=838)\end{array}$ & $P$-value ${ }^{b}$ \\
\hline Total energy (kcal/day) & $1799(498)$ & $1819(519)$ & 0.271 & $1989(528)$ & $<0.001$ \\
\hline \multicolumn{6}{|l|}{ Micronutrients (without supplement) } \\
\hline Calcium (mg/day) & $534(230)$ & $513(252)$ & 0.011 & $557(243)$ & 0.004 \\
\hline $\operatorname{Iron}(\mathrm{mg} /$ day $)$ & $13.8(6.6)$ & $13.3(5.4)$ & 0.020 & $15.1(10.2)$ & $<0.001$ \\
\hline Phosphate (mg/day) & $1053(331)$ & $1037(350)$ & 0.162 & $1130(332)$ & $<0.001$ \\
\hline Sodium (mg/day) & $4141(1640)$ & $4218(1811)$ & 0.209 & $4520(1875)$ & $<0.001$ \\
\hline Potassium (mg/day) & $2910(1037)$ & $2867(1037)$ & 0.241 & $3065(1085)$ & $<0.001$ \\
\hline Vitamin A ( $\mu \mathrm{g} /$ day $)$ & $709(489)$ & $688(501)$ & 0.218 & $731(414)$ & 0.212 \\
\hline Retinol ( $\mu \mathrm{g} /$ day $)$ & $112(169)$ & $122(322)$ & 0.119 & $112(105)$ & 0.943 \\
\hline Carotene ( $\mu \mathrm{g} /$ day $)$ & $3419(2600)$ & $3257(2166)$ & 0.069 & $3551(2270)$ & 0.149 \\
\hline Vitamin B1 (mg/day) & $1.29(3.05)$ & $1.30(2.22)$ & 0.951 & $1.40(1.65)$ & 0.361 \\
\hline Vitamin B2 (mg/day) & $1.12(0.59)$ & $1.08(0.45)$ & 0.091 & $1.20(0.59)$ & 0.001 \\
\hline Vitamin B6 (mg/day) & $2.08(1.61)$ & $2.00(0.72)$ & 0.138 & $2.20(0.87)$ & 0.032 \\
\hline Vitamin C (mg/day) & $118.9(79)$ & $117(78)$ & 0.512 & $112(69)$ & 0.011 \\
\hline Vitamin E (mg/day) & $12.7(5.8)$ & $12.6(7.3)$ & 0.713 & $13.2(5.9)$ & 0.012 \\
\hline Niacin (mg/day) & $17.8(7.1)$ & $17.9(7.4)$ & 0.832 & $20.2(8.1)$ & $<0.001$ \\
\hline Folic acid ( $\mu \mathrm{g} /$ day) & $249(140)$ & $240(108)$ & 0.071 & $255(128)$ & 0.232 \\
\hline Zinc (mg/day) & $9.9(6.9)$ & $10.2(9.1)$ & 0.323 & $10.6(4.6)$ & 0.007 \\
\hline
\end{tabular}

${ }^{\mathrm{a} P}$-values comparing control and non-erosive reflux disease (NERD).

${ }^{\mathrm{b}} P$-values comparing control and erosive esophagitis.

Values are expressed as the mean (SD).

$P$-values were derived from $t$ test.

\section{Effects of Micronutrients on Non-erosive Reflux Disease and Erosive Esophagitis}

In an adjusted analysis for the quartile of micronutrients, higher intake of calcium $(P$ for trend $<0.001)$, iron $(P$ for trend $<0.001)$, phosphate $(P$ for trend $<0.001)$, vitamin A $(P$ for trend $=0.007)$, retinol, vitamin B2 $(P$ for trend $<0.001)$, vitamin B6 ( $P$ for trend $=0.007)$, and folic acid $(P$ for trend $=0.020)$ reduced NERD (Table 3). Even though almost all micronutrients affected erosive esophagitis in unadjusted analysis, only the fourth quartile of vitamin $\mathrm{C}$ decreased erosive esophagitis compared to the lowest quartile in adjusted analysis (OR, 0.78; 95\% CI, 0.62-0.98; Supplementary Table 1). The second quartile of sodium decreased erosive esophagitis compared to the lowest quartile (OR, 0.74; 95\% CI, 0.59-0.94). Erosive esophagitis was associated with male sex, higher BMI, negative $H$. pylori, current smoker, current drinker, and high total energy intake (data not shown). NERD was associated with female sex, younger age, current smoker, and high total energy intake (data not shown).

\section{Effects of Micronutrients on Non-erosive Reflux Disease by Gender (Adjusted Analysis)}

In men, high calcium intake (OR, 0.72; 95\% CI, 0.55-0.95) and moderate intake of phosphate (OR, 0.74; 95\% CI, 0.57-0.97) and potassium (OR, 0.75; 95\% CI, 0.58-0.97) reduced NERD (Table 4). In women, high dietary intake of calcium (OR, 0.77; 95\% CI, 0.61-0.98) and potassium (OR, 0.75; 95\% CI, 0.57-1.00), and moderate to high intake of iron and phosphate reduced NERD (Table 4). High dietary intake of vitamin A (OR, 0.76; 95\% CI, 0.59-0.97), retinol (OR, 0.75; 95\% CI, 0.59-0.96), vitamin B2 (OR, 0.74; 95\% CI, 0.56-0.97), and vitamin B6 (OR, 0.73; 95\% CI, 0.55-0.97) also reduced NERD (Table 4).

\section{Effects of Micronutrients on Erosive Esophagitis by Gender (Adjusted Analysis)}

In men, any dietary intake of micronutrients had no association with erosive esophagitis and high dietary intake of retinol increased erosive esophagitis in women (Supplementary Table 2). 
Table 3. Effects of Micronutrients on Non-erosive Reflux Disease

\begin{tabular}{|c|c|c|c|c|c|}
\hline \multirow{2}{*}{ Daily intake } & \multicolumn{2}{|c|}{ Unadjusted } & \multicolumn{3}{|c|}{ Adjusted $^{\mathrm{a}}$} \\
\hline & OR $(95 \% \mathrm{CI})$ & $P$-value & OR $(95 \% \mathrm{CI})$ & $P$-value & $P$ for trend \\
\hline \multicolumn{6}{|l|}{ Calcium (mg/day) } \\
\hline 1st quartile $(<376)$ & 1 & & 1 & & \\
\hline 2nd quartile $(376-<510)$ & $0.75(0.63-0.91)$ & 0.003 & $0.74(0.61-0.89)$ & 0.002 & \\
\hline 3 rd quartile $(510-<644)$ & $0.69(0.57-0.83)$ & $<0.001$ & $0.67(0.55-0.83)$ & $<0.001$ & \\
\hline 4th quartile $(\geq 644)$ & $0.72(0.59-0.87)$ & 0.001 & $0.66(0.53-0.82)$ & $<0.001$ & $<0.001$ \\
\hline \multicolumn{6}{|l|}{$\operatorname{Iron}(\mathrm{mg} /$ day) } \\
\hline 1st quartile $(<10.2)$ & 1 & & 1 & & \\
\hline 2nd quartile $(10.2-<13.2)$ & $0.92(0.77-1.10)$ & 0.381 & $0.86(0.70-1.05)$ & 0.141 & \\
\hline 3rd quartile $(13.2-<16.1)$ & $0.76(0.63-0.92)$ & 0.005 & $0.68(0.54-0.86)$ & 0.001 & \\
\hline 4th quartile $(\geq 16.1)$ & $0.78(0.65-0.95)$ & 0.011 & $0.68(0.53-0.87)$ & 0.002 & $<0.001$ \\
\hline \multicolumn{6}{|l|}{ Phosphate (mg/day) } \\
\hline 1st quartile $(<828)$ & 1 & & 1 & & \\
\hline 2nd quartile $(828-<1033)$ & $0.92(0.76-1.10)$ & 0.349 & $0.83(0.68-1.01)$ & 0.069 & \\
\hline 3rd quartile $(1033-<1238)$ & $0.89(0.74-1.08)$ & 0.223 & $0.77(0.62-0.96)$ & 0.022 & \\
\hline 4th quartile $(\geq 1238)$ & $0.84(0.69-1.02)$ & 0.078 & $0.63(0.47-0.84)$ & 0.001 & $<0.001$ \\
\hline \multicolumn{6}{|l|}{ Vitamin A ( $\mu \mathrm{g} /$ day $)$} \\
\hline 1st quartile $(<434)$ & 1 & & 1 & & \\
\hline 2nd quartile (434-< 643 ) & $0.83(0.69-1.00)$ & 0.049 & $0.81(0.67-0.98)$ & 0.033 & \\
\hline 3rd quartile $(643-<852)$ & $0.87(0.72-1.05)$ & 0.151 & $0.84(0.69-1.02)$ & 0.079 & \\
\hline 4th quartile $(\geq 852)$ & $0.82(0.68-0.99)$ & 0.043 & $0.78(0.64-0.96)$ & 0.022 & 0.007 \\
\hline \multicolumn{6}{|l|}{ Retinol ( $\mu \mathrm{g} /$ day $)$} \\
\hline 1st quartile $(<44.9)$ & 1 & & 1 & & \\
\hline 2nd quartile $(44.9-<87.7)$ & $0.82(0.68-0.99)$ & 0.043 & $0.79(0.65-0.96)$ & 0.021 & \\
\hline 3rd quartile $(87.7-<130.4)$ & $0.93(0.77-1.12)$ & 0.462 & $0.87(0.72-1.06)$ & 0.163 & \\
\hline 4th quartile $(\geq 130.4)$ & $0.85(0.70-1.02)$ & 0.089 & $0.73(0.59-0.90)$ & 0.003 & 0.021 \\
\hline \multicolumn{6}{|l|}{ Vitamin B2 (mg/day) } \\
\hline 1st quartile $(<0.82)$ & 1 & & 1 & & \\
\hline 2nd quartile $(0.82-<1.07)$ & $0.93(0.77-1.12)$ & 0.471 & $0.86(0.71-1.05)$ & 0.149 & \\
\hline 3rd quartile $(1.07-<1.33)$ & $0.80(0.66-0.98)$ & 0.023 & $0.70(0.57-0.86)$ & 0.001 & \\
\hline 4th quartile $(\geq 1.33)$ & $0.86(0.71-1.03)$ & 0.109 & $0.68(0.54-0.87)$ & 0.002 & $<0.001$ \\
\hline \multicolumn{6}{|l|}{ Vitamin B6 (mg/day) } \\
\hline 1st quartile $(<1.56)$ & 1 & & 1 & & \\
\hline 2nd quartile $(1.56-<1.99)$ & $0.92(0.76-1.11)$ & 0.391 & $0.87(0.72-1.06)$ & 0.178 & \\
\hline 3rd quartile $(1.99-<2.43)$ & $0.84(0.69-1.02)$ & 0.069 & $0.77(0.62-0.96)$ & 0.022 & \\
\hline 4th quartile $(\geq 2.43)$ & $0.87(0.72-1.05)$ & 0.148 & $0.75(0.58-0.96)$ & 0.023 & 0.007 \\
\hline \multicolumn{6}{|l|}{ Folic acid $(\mu \mathrm{g} /$ day $)$} \\
\hline 1st quartile $(<174)$ & 1 & & 1 & & \\
\hline 2nd quartile $(174-<232)$ & $0.89(0.75-1.08)$ & 0.271 & $0.89(0.73-1.08)$ & 0.243 & \\
\hline 3rd quartile $(232-<290)$ & $0.79(0.66-0.96)$ & 0.021 & $0.78(0.63-0.96)$ & 0.021 & \\
\hline 4th quartile ( $\geq 290)$ & $0.83(0.69-1.01)$ & 0.059 & $0.77(0.62-0.96)$ & 0.022 & 0.02 \\
\hline
\end{tabular}

${ }^{a}$ Adjusted for age, gender, body mass index, total energy intake, presence of hiatal hernia, presence of Helicobacter pylori, and smoking. Age and body mass index were continuous variables. Total energy intake was quartile.

\section{Discussion}

This study showed gender-specific effects of the dietary intake of micronutrients on NERD and erosive esophagitis. While higher dietary intake of calcium, iron, phosphate, vitamin A, retinol, vitamin B2, vitamin B6, and folic acid reduced the risk of NERD, only vitamin $\mathrm{C}$ reduced the risk of erosive esophagitis. In gender-specific 
Table 4. Effects of Micronutrients on Non-erosive Reflux Disease by Gender

\begin{tabular}{|c|c|c|c|c|c|}
\hline \multirow{2}{*}{\multicolumn{2}{|c|}{ Daily intake }} & \multicolumn{2}{|l|}{ Men } & \multicolumn{2}{|l|}{ Women } \\
\hline & & \multirow{2}{*}{$\frac{\text { Adjusted } \mathrm{OR}^{\mathrm{a}}(95 \% \mathrm{CI})}{1}$} & \multirow[t]{2}{*}{$P$-value ${ }^{\mathrm{a}}$} & \multirow{2}{*}{$\begin{array}{c}\text { Adjusted } \mathrm{OR}^{\mathrm{a}}(95 \% \mathrm{CI}) \\
1\end{array}$} & \multirow[t]{2}{*}{$P$-value ${ }^{\text {a }}$} \\
\hline Calcium (mg/day) & 1st group & & & & \\
\hline & 2nd group & $0.90(0.71-1.15)$ & 0.411 & $0.86(0.68-1.08)$ & 0.191 \\
\hline & 3rd group & $0.72(0.55-0.95)$ & 0.018 & $0.77(0.61-0.98)$ & 0.032 \\
\hline \multirow[t]{3}{*}{ Iron (mg/day) } & 1st group & 1 & & 1 & \\
\hline & 2nd group & $0.97(0.75-1.25)$ & 0.792 & $0.74(0.58-0.94)$ & 0.011 \\
\hline & 3 rd group & $0.75(0.56-1.01)$ & 0.059 & $0.79(0.62-1.01)$ & 0.059 \\
\hline \multirow[t]{3}{*}{ Phosphate (mg/day) } & 1st group & 1 & & 1 & \\
\hline & 2nd group & $0.74(0.57-0.97)$ & 0.032 & $0.74(0.57-0.94)$ & 0.021 \\
\hline & 3rdgroup & $0.73(0.53-1.02)$ & 0.061 & $0.69(0.50-0.94)$ & 0.019 \\
\hline \multirow[t]{3}{*}{ Sodium (mg/day) } & 1st group & 1 & & 1 & \\
\hline & 2nd group & $0.90(0.70-1.16)$ & 0.432 & $0.87(0.68-1.11)$ & 0.261 \\
\hline & 3rd group & $0.86(0.65-1.13)$ & 0.281 & $1.16(0.90-1.50)$ & 0.251 \\
\hline \multirow[t]{3}{*}{ Potassium (mg/day) } & 1st group & 1 & & 1 & \\
\hline & 2nd group & $0.75(0.58-0.97)$ & 0.030 & $0.97(0.77-1.23)$ & 0.803 \\
\hline & 3rdgroup & $0.76(0.57-1.02)$ & 0.069 & $0.75(0.57-1.00)$ & 0.051 \\
\hline \multirow[t]{3}{*}{ Vitamin A ( $\mu \mathrm{g} /$ day $)$} & 1st group & 1 & & 1 & \\
\hline & 2nd group & $0.86(0.67-1.11)$ & 0.242 & $0.86(0.68-1.08)$ & 0.201 \\
\hline & 3rd group & $0.87(0.67-1.12)$ & 0.271 & $0.76(0.59-0.97)$ & 0.029 \\
\hline \multirow[t]{3}{*}{ Retinol ( $\mu \mathrm{g} /$ day) } & 1st group & 1 & & 1 & \\
\hline & 2nd group & $0.96(0.75-1.24)$ & 0.772 & $0.85(0.67-1.06)$ & 0.151 \\
\hline & 3rdgroup & $0.94(0.73-1.22)$ & 0.651 & $0.75(0.59-0.96)$ & 0.020 \\
\hline \multirow[t]{3}{*}{ Vitamin B2 (mg/day) } & 1st group & 1 & & 1 & \\
\hline & 2nd group & $0.88(0.68-1.14)$ & 0.353 & $0.80(0.63-1.02)$ & 0.071 \\
\hline & 3rd group & $0.79(0.58-1.07)$ & 0.131 & $0.74(0.56-0.97)$ & 0.027 \\
\hline \multirow[t]{3}{*}{ Vitamin B6 (mg/day) } & 1st group & 1 & & 1 & \\
\hline & 2nd group & $0.86(0.67-1.12)$ & 0.272 & $0.78(0.61-0.99)$ & 0.043 \\
\hline & 3rd group & $0.83(0.61-1.12)$ & 0.221 & $0.73(0.55-0.97)$ & 0.028 \\
\hline \multirow[t]{3}{*}{ Vitamin C (mg/day) } & 1st group & 1 & & 1 & \\
\hline & 2nd group & $0.79(0.61-1.02)$ & 0.071 & $0.86(0.68-1.09)$ & 0.212 \\
\hline & 3rdgroup & $0.96(0.74-1.23)$ & 0.743 & $0.94(0.74-1.20)$ & 0.631 \\
\hline \multirow[t]{3}{*}{ Folic acid ( $\mu \mathrm{g} /$ day $)$} & 1st group & 1 & & 1 & \\
\hline & 2nd group & $0.84(0.65-1.09)$ & 0.191 & $1.08(0.85-1.37)$ & 0.523 \\
\hline & 3rd group & $0.89(0.68-1.17)$ & 0.401 & $0.86(0.66-1.12)$ & 0.261 \\
\hline
\end{tabular}

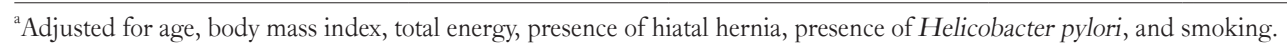

Body mass index were continuous variables.

analysis, high dietary intake of calcium reduced NERD in men and high dietary intake of many micronutrients reduced NERD in women. High dietary intake of retinol increased erosive esophagitis in women but any micronutrients had no effect on erosive esophagitis in men.

Interestingly, NERD strongly correlated with many dietary micronutrients. High intake of calcium, iron, phosphate, vitamin A, retinol, vitamin B2, vitamin B6, and folic acid decreased NERD. High dietary intake of vitamin $\mathrm{C}$ decreased erosive esophagitis. In a previous small study (total study population is 371 ), micronutri- ents had no effect on GERD. ${ }^{4}$ Plausible mechanisms of the inverse relationship of NERD with calcium, iron, and phosphate intake are unknown. We suggest that micronutrients affect gastric acidity and lower esophageal sphincter (LES) tone for the following reasons. Both calcium and iron can bind chloride, thus decreasing intragastric acidity. Calcium bicarbonate has been used as an antacid. The myogenic component of LES is calcium dependent, ${ }^{17}$ and extrinsic neurogenic control of LES contraction is primarily vagal and cholinergic. ${ }^{18}$ In vitro experiments showed that acetylcholine-induced contraction decreases with decreasing extracellular calcium ions and 
can be blocked by incubation in a calcium ion-free solution. ${ }^{19}$ The study suggested that contraction in response to acetylcholine is mediated by an influx of extracellular ionized calcium. ${ }^{19}$ Actually, calcium channel blockers have been shown to decrease LES pressure. Therefore, insufficient calcium intake may induce LES relaxation in vivo.

In this study, antioxidants (vitamin A, retinol, vitamin B2, vita$\min \mathrm{B} 6$, and folic acid) were associated with $22-32 \%$ reduction in the risk of NERD and vitamin C had an association with $22 \%$ reduction in the risk of erosive esophagitis. In a previous study, intake of dietary antioxidants (vitamin $\mathrm{C}$ and beta-carotene), fruits, and vegetables was inversely associated with the risk of Barrett's esophagus, but supplement intake had no association with Barrett's esophagus. ${ }^{11}$ In a Chinese cross-sectional study, vitamin $\mathrm{C}$ was inversely related with reflux esophagitis. ${ }^{20}$ Some dietary micronutrients was associated with Barrett's esophagus, ${ }^{10,11}$ but dietary micronutrients had no effect on GERD. ${ }^{4,12}$ The sample size of previous studies were relatively small and so they may not conclude significant results. Erosive esophagitis had no association with micronutrient except vitamin $\mathrm{C}$, whereas it was strongly associated with body mass index, negative $H$. pylori, and total energy intake in this study and also previous our studies. ${ }^{9,14,21}$

This is the first study about the gender-specific effect of micronutrients on NERD and erosive esophagitis. Gender-specific analysis showed that the effect of micronutrients on NERD was more prominent in women than men. In men, high calcium intake and moderate intake of phosphate and potassium reduced NERD. In women, high intake of calcium and potassium, and moderate to high intake of iron and phosphate reduced NERD. High intake of vitamin A, retinol, vitamin B2, and vitamin B6 also reduced NERD. The effect of micronutrient on NERD in women was similar with that in the overall population. Less prominent association and borderline association between micronutrient and NERD in men may be related to low prevalence of NERD in men (6.8\%) comparing to women (9.1\%). Dietary intake of micronutrients had no association with erosive esophagitis in men and high dietary intake of retinol increased erosive esophagitis in women.

The cause of gender discrepancy of dietary micronutrient effect on NERD is unclear. Gender difference may exist in sensitivity of inflammation or the pathogenesis of distal esophageal inflammation. First, female hormone, estrogen has anti-inflammatory activities in animal studies. ${ }^{22,23}$ Esophageal damage increased in male rats and ovariectomised rats comparing to female rats and the aggravated esophageal damage was attenuated by $17 \beta$-estradiol in a recent animal study. ${ }^{22}$ Inflammatory cytokines have an association with reflux esophagitis ${ }^{24,25}$ and their expression has gender difference. ${ }^{24}$ The gender difference in sex hormones and inflammatory cytokines may affect the inflammation of distal esophagus by micronutrients. Second, gender difference in esophageal nociception may be a plausible mechanism. Up-regulation of transient receptor potential cation channel subfamily V member 1 (TRPV1) in esophageal mucosa of NERD and reflux esophagitis patients comparing to healthy control was observed. ${ }^{26,27}$ TRPV1 looks as one of the important mechanisms of GERD symptoms. ${ }^{28,29} \mathrm{Up}$-regulation of TRPV1 in distal esophageal mucosa may be the potential mechanism of the visceral hypersensitivity in NERD. Gender difference in TRPV1 expression by external factors such as acid or micronutrients might contribute to different effect of micronutrient on NERD by gender. It is needed to elucidate the mechanism of gender discrepancy of the effect of dietary micronutrients on GERD in the future.

Regardless of the insufficient evidence of the effect of dietary habits and dietary modification on GERD, dietary modification have been recommended as first-line therapies. ${ }^{30}$ Evidence-based Japanese guideline for GERD recommend that lifestyle modifications with PPI therapy is effective for GERD. ${ }^{31}$ Our results that sufficient of micronutrients have an inverse association with NERD provide the evidence of the dietary modification to prevent or manage NERD.

This study has some strengths. First, we used 3-day records, the gold standard of diet assessment to evaluate dietary intake. While Food frequency questionnaire is a semi-quantitative assessment method, 3-day records quantify the diet items and nutrient components. Therefore, it provides the most accurate evaluation of food intake compared with other diet assessment methods. Second, we separately analyzed NERD and erosive esophagitis, which are different phenotypes of GERD. ${ }^{13}$ The third, the large size allowed us to evaluate many confounding factors, including demographic factors and clinical factors, and permitted us to perform more detailed analyses. Fourth, we evaluated GERD using endoscopy, current infection of $H$. pylori, and body mass index by direct measurement. Endoscopy allowed an accurate evaluation of erosive esophagitis according to the Los Angeles classification system. We could adjust for $H$. pylori, which has strongly inverse association with erosive esophagitis in Asia. ${ }^{14}$ Lastly, we assessed the genderspecific contribution of dietary micronutrients on NERD and erosive esophagitis.

Nevertheless, this study has some limitations. First, health screening may change the diet habit thereby result in a selection bias. Second, physical activity, which is associated with obesity, was not adjusted in this study. However, a previous study suggested 
that physical activity had no association with erosive esophagitis. ${ }^{5}$ Psychologic distress, which may be affected on NERD, was not adjusted. Food consumption pattern such as speed or frequency of food consumption also was not adjusted. Third, we did not validate this result in other groups. Therefore, further studies in other institutes or countries need to acquire generalizability. Finally, the crosssectional study is insufficient to provide the definitive causality.

In conclusion, sufficient intake of micronutrients and antioxidants reduced NERD but the effect of dietary micronutrient on erosive esophagitis was minimal. Erosive esophagitis had an association with high total energy intake. Gender-specific analysis showed more prominent effect of micronutrient on NERD in women than men. Gender-specific different approaches may need to manage and prevent NERD and erosive esophagitis. Mechanism of different effect of dietary micronutrients on NERD and erosive esophagitis and longitudinal studies for this topic need to be researched in the near future.

\section{Supplementary Materials}

Note: To access the supplementary tables mentioned in this article, visit the online version of Journal of Neurogastroenterology and Motility at http://www.jnmjournal.org/, and at https://doi. org/10.5056/jnm18114.

Acknowledgement: Authors have special thanks to Hyun Hee Kang, Kyoung A Ryu, and Min Kyong Yoo for acquiring the nutritional data.

\section{Financial support: None.}

\section{Conflicts of interest: None.}

Author contributions: $\mathrm{Su}$ Youn Nam had full access to all of the data in the study and takes responsibility for the integrity of the data and the accuracy of the data analysis, and contributed to the study concept and design; Su Youn Nam, Kum Hei Ryu, and Bum Joon Park performed endoscopic procedures; Yeong-Ah Cho converted the diet records of each nutrient to electrical data; and all authors have read and approved the final version of the manuscript.

\section{References}

1. Nam SY, Choi IJ, Ryu KH, Park BJ, Kim HB, Nam BH. Abdominal visceral adipose tissue volume is associated with increased risk of erosive esophagitis in men and women. Gastroenterology 2010;139:1902-1911, e2.

2. El-Serag HB, Sweet S, Winchester CC, Dent J. Update on the epidemiology of gastro-oesophageal reflux disease: a systematic review. Gut 2014;63:871-880.

3. Kim N, Lee SW, Cho SI, et al. The prevalence of and risk factors for erosive oesophagitis and non-erosive reflux disease: a nationwide multicentre prospective study in Korea. Aliment Pharmacol Ther 2008;27:173-185.

4. El-Serag HB, Satia JA, Rabeneck L. Dietary intake and the risk of gastro-oesophageal reflux disease: a cross sectional study in volunteers. Gut 2005;54:11-17.

5. Festi D, Scaioli E, Baldi F, et al. Body weight, lifestyle, dietary habits and gastroesophageal reflux disease. World J Gastroenterol 2009;15:16901701.

6. Pehl C, Waizenhoefer A, Wendl B, Schmidt T, Schepp W, Pfeiffer A. Effect of low and high fat meals on lower esophageal sphincter motility and gastroesophageal reflux in healthy subjects. Am J Gastroenterol 1999;94:1192-1196

7. Shapiro M, Green C, Bautista JM, et al. Assessment of dietary nutrients that influence perception of intra-oesophageal acid reflux events in patients with gastro-oesophageal reflux disease. Aliment Pharmacol Ther 2007;25:93-101.

8. Zheng Z, Nordenstedt H, Pedersen NL, Lagergren J, Ye W. Lifestyle factors and risk for symptomatic gastroesophageal reflux in monozygotic twins. Gastroenterology 2007;132:87-95.

9. Nam SY, Park BJ, Cho YA, et al. Different effects of dietary factors on reflux esophagitis and non-erosive reflux disease in 11,690 Korean subjects. J Gastroenterol 2017;52:818-829.

10. Corley DA, Kubo A, Levin TR, et al. Iron intake and body iron stores as risk factors for Barrett's esophagus: a community-based study. Am J Gastroenterol 2008;103:2997-3004

11. Kubo A, Levin TR, Block G, et al. Dietary antioxidants, fruits, and vegetables and the risk of Barrett's esophagus. Am J Gastroenterol 2008;103:1614-1623.

12. Murphy SJ, Anderson LA, Ferguson HR, et al. Dietary antioxidant and mineral intake in humans is associated with reduced risk of esophageal adenocarcinoma but not reflux esophagitis or Barrett's esophagus. J Nutr 2010;140:1757-1763.

13. Hershcovici T, Fass R. Nonerosive reflux disease (NERD) - an update. J Neurogastroenterol Motil 2010;16:8-21.

14. Nam SY, Choi IJ, Ryu KH, Kim BC, Kim CG, Nam BH. Effect of Helicobacter pylori infection and its eradication on reflux esophagitis and reflux symptoms. Am J Gastroenterol 2010;105:2153-2162.

15. Armstrong D, Bennett JR, Blum AL, et al. The endoscopic assessment of esophagitis: a progress report on observer agreement. Gastroenterology 1996;111:85-92.

16. Said RM, Cheah PL, Chin SC, Goh KL. Evaluation of a new biopsy urease test: pronto dry, for the diagnosis of Helicobacter pylori infection. Eur J Gastroenterol Hepatol 2004;16:195-199.

17. Biancani P, Hillemeier C, Bitar KN, Makhlouf GM. Contraction mediated by $\mathrm{Ca} 2+$ influx in esophageal muscle and by $\mathrm{Ca}^{2+}$ release in the LES. Am J Physiol 1987;253(6 Pt 1):G760-G766.

18. Dodds WJ, Dent J, Hogan WJ, Arndorfer RC. Effect of atropine on 
esophageal motor function in humans. Am J Physiol 1981;240:G290G296.

19. Sohn UD, Chiu TT, Bitar KN, Hillemeier C, Behar J, Biancani P. Calcium requirements for acetylcholine-induced contraction of cat esophageal circular muscle cells. Am J Physiol 1994;266(2 Pt 1):G330-G338.

20. Wu P, Zhao XH, Ai ZS, et al. Dietary intake and risk for reflux esophagitis: a case-control study. Gastroenterol Res Pract 2013;2013:691026.

21. Nam SY, Choi IJ, Nam BH, Park KW, Kim CG. Obesity and weight gain as risk factors for erosive oesophagitis in men. Aliment Pharmacol Ther 2009;29:1042-1052.

22. Masaka T, lijima K, Endo H. Gender differences in oesophageal mucosal injury in a reflux oesophagitis model of rats. Gut 2013;62:6-14.

23. Velders M, Schleipen B, Fritzemeier KH, Zierau O, Diel P. Selective estrogen receptor- $\beta$ activation stimulates skeletal muscle growth and regeneration. FASEB J 2012;26:1909-1920.

24. Nam SY, Choi IJ, Ryu KH, et al. The effect of abdominal visceral fat, circulating inflammatory cytokines, and leptin levels on reflux esophagitis. J Neurogastroenterol Motil 2015;21:247-254.

25. Tseng PH, Yang WS, Liou JM, et al. Associations of circulating gut hormone and adipocytokine levels with the spectrum of gastroesophageal reflux disease. PLoS One 2015;10:e0141410.
26. Yoshida N, Kuroda M, Suzuki T, et al. Role of nociceptors/neuropeptides in the pathogenesis of visceral hypersensitivity of nonerosive reflux disease. Dig Dis Sci 2013;58:2237-2243.

27. Guarino MP, Cheng L, and Ma J, et al. Increased TRPV1 gene expression in esophageal mucosa of patients with non-erosive and erosive reflux disease. Neurogastroenterol Motil 2010;22:746-751, e219.

28. Kim JJ, Kim N, Choi YJ, Kim JS, Jung HC. Increased TRPV1 and PAR2 mRNA expression levels are associated only with the esophageal reflux symptoms, but not with the extra esophageal reflux symptoms. Medicine (Baltimore) 2016;95:e4387.

29. Ma J, Altomare A, Guarino M, et al. HCl-induced and ATP-dependent upregulation of TRPV1 receptor expression and cytokine production by human esophageal epithelial cells. Am J Physiol Gastrointest Liver Physiol 2012;303:G635-G645.

30. DeVault KR, Castell DO. Updated guidelines for the diagnosis and treatment of gastroesophageal reflux disease. Am J Gastroenterol 2005;100:190-200.

31. Iwakiri K, Kinoshita Y, Habu Y, et al. Evidence-based clinical practice guidelines for gastroesophageal reflux disease 2015. J Gastroenterol 2016;51:751-767. 